\title{
Effects of Bacillus subtilis DSM 32315 on Immunity, Nutrient Transporters and Functional Diversity of Cecal Microbiome of Broiler Chickens in Necrotic Enteritis Challenge
}

\author{
Bello Musa Bodinga ${ }^{1,2}$, Khawar Hayat ${ }^{1}$, Xinshuai $\mathrm{Liu}^{1}$, Jinghui Zhou ${ }^{1}$, Xin Yang ${ }^{1}$, Abdullahi Ismaila ${ }^{2}$, Rab Nawaz \\ Soomro ${ }^{3}$, Zhouzheng Ren ${ }^{1}$, Wenming Zhang ${ }^{4}$ and XiaoJun Yang ${ }^{1}$ * \\ ${ }^{I}$ College of Animal Science and Technology, Northwest Agriculture and Forestry University, Yangling, 712100, China; \\ ${ }^{2}$ Department of Agricultural Science, Shehu Shagari College of Education, Sokoto, Sokoto State, P.M.B 2129 Nigeria; \\ ${ }^{3}$ Livestock and Dairy Development Department Quetta, 87300 Baluchistan, Pakistan; \\ ${ }^{4}$ Evonik Degussa (China) Co., Ltd., Beijing 100600, China; \\ "Corresponding author’s Email: yangxj@ nwsuaf.edu.cn; ORCID: 0000-0001-9702-7039
}

Received: 12 Aug. 2020

Accepted: 22 Sept. 2020

\begin{abstract}
This study was conducted to determine the effects of Bacillus subtilis DSM 32315 probiotic and antibiotic enramycin in broiler chickens with Clostridium perfringens induced-Necrotic enteritis on cecal microbial populations, functional diversity, nutrients transporters and cytokines mRNA expression. Day-old broilers $(n=360)$, Arbor Acre were randomly assigned to three dietary treatments such as control, basal diet fed-group only; antibiotic, basal diet plus enramycin $5 \mathrm{mg} / \mathrm{kg}$; and probiotic group, basal diet plus Bacillus subtilis $2 \times 10^{9} \mathrm{CFU} / \mathrm{g}$. Antibiotic and probiotic fed groups was challenged with Clostridium perfringens at day1, and from day 14 to day 21 . The results of present study showed that broiler chickens supplemented with antibiotic and probiotic significantly exhibited higher abundance of gut beneficial bacteria at the 21 and 35 days of age, while upregulated the expression of anti-inflammatory cytokine enterleukin-10 and secretory immunoglobulin-A. Expression of proinflammatory cytokines interleukin-6 tumor necrosis factor alpha, and interferon gamma were downregulated. Nutrient transporters of Peptide transporter-1, L amino transporter-2 and Cationic amino acid transporter-2 were upregulated in supplemented groups. More so, glucose transporter-2 Sodium glucose transporter-1, Solute carrier family 3, member 1, carbohydrates and vitamin metabolism cofactor enriched in probiotic fed-group, while control group exhibited up-regulation in interleukin-6, tumor necrosis factor alpha, and interferon gamma. Overall, supplementation of Bacillus subtilis DMS 32315 reduced the negative impact of necrotic enteritis in broiler chickens, and enhanced the gut-microbial community.
\end{abstract}

Keywords: Antibiotic growth promoter, Bacillus subtilis, Clostridium perfringens, Immune response, probiotic

\section{INTRODUCTION}

Antibiotic growth promoters (AGPs), are substantially used in Agriculture to improve the economic value of animals through increased growth and feed efficiency, while indirectly they are used to control some enteric diseases (Gadde et al., 2017). Mismanagement in the use of AGPs in agricultural animals leaded to drug-resistant bacteria "superbugs", drug residue and its possible negative consequences in the intestinal microbial homeostasis (Bai et al., 2017). Moreover, regulatory agencies and consumer demands on animals produced free from antibiotics mandated agricultural industry to make changes in the use of AGPs in animal production (WHO,
2017). Thus, it led to withdrawal or restrictions of antimicrobial use in poultry production in many parts of the world, this resulted to many consequences, among others are prevalence of enteritis related diseases commonly Necrotic Enteritis (NE) and widespread of illdefined intestinal dysbacteriosis which is associated with reduced nutrients digestibility in poultry (Latorre et al., 2014). Necrotic enteritis is a serious disease in poultry caused by Clostridium perfringens, a gram positive, ubiquitous and anaerobic bacterium, found at a level less than $10^{5} \mathrm{CFU} / \mathrm{g}$ of the intestinal contents of healthy birds, but disturbances in normal intestinal

Microflora may cause rapid proliferation of $C$. perfringens, increasing bacterial numbers to $10^{7}$ to $10^{9}$ 
CFU/g of digesta resulting in the development of clinical NE (Opengart et al., 2013). Similarly, NE was characterized as the 'clinical and subclinical form', the subclinical form of NE does much more harm to animals than the clinical form due to its persistent in the flock without any clinical manifestation, no peak of mortality, and are associated with reduced feed intake and weight gain, and increased feed conversion ratio (Dahiya et al., 2006; Timbermont and Immerseel, 2011). Besides the health risk imposed by NE to animals, it was assessed to cost $\$ 6$ billion loss to the poultry industry annually (Wade and Keyburn, 2015). Thus, it was imperative to explore other alternatives to AGPs that can maintain both productive potentials and gut health of the animals (Bai et al., 2017). Previous studies proved that, among the basic strategies that can be employed to cope with the loss of AGPs, and to control NE in broiler chickens, is the incorporation of probiotic into the animal's diet, which maintains animal health, growth and feed efficiency (Zhao and Kim, 2015; Musa Bodinga et al., 2019). An increase in performance of animals can be related to the changes in the microbial population dynamics of the gastrointestinal tract (GIT) of the animals creating favorable microbial environment as a result of shift in balance between beneficial and harmful microbes (Cao et al., 2012). Beneficial bacteria such as 'Bacillus, Bifidobacterium, Enterococcus, Lactobacillus, Lactococcus, and Streptococcus" were commonly used as probiotics in animal production (Simon et al., 2001). Nevertheless, in recent time, Bacillus based probiotics are gaining acceptance as potential alternative to AGPs in the poultry industry. Perhaps this could be due to their distinct advantage in the production of naturally synthesized peptides, production of beneficial metabolites, modification of gut microbial structure, and stimulation of various immune modulators (Lee et al., 2010; Sumi et al., 2015). Bacillus spores were resistant to antimicrobial low $\mathrm{pH}$, bile salts, and harsh conditions of the GIT. (Shivaramaiah et al., 2011). The nutrient transport system played a vital role in the small intestine of the birds, where specific nutrients were conveyed by specific transporters found at the brush border of the small intestines for absorption by enterocytes (Shivaramaiah et al., 2011). Monosaccharides (glucose, galactose, fructose and mannose) were mediated at the brush border membrane by Sodium dependent glucose and galactose transporter1 (SGLT1), and exit of glucose across the basolateral membrane was mediated by facilitated transporter $\mathrm{Na}^{+}$independent glucose, galactose and fructose transporter 2 (GLUT2) the cell via glucose transporter-2 (Shivaramaiah et al., 2011). Where peptide transporter-1 was responsible for absorption of the most di and tri-peptides, and functions as obligatory exchangers of cationic amino acids, CAT1 was responsible for the efflux of cationic amino acids (Shivaramaiah et al., 2011). Similarly, the composition of gut microbiota were hypothesized to affect many host functions including nutrients' utilization of gut epithelium and development of gut immune system (Hill et al., 2010). In our previous study, it was discovered that supplementation of Lactobacillus fermentum 1.2029 probiotic in $C$. perfringens challenged broiler, modulated toll-like receptors and some cytokines related genes (Cao et al., 2012). Nonetheless, the immunopathology of NE in broiler chickens was not fully understood ( $\mathrm{Oh}$ and Lillehoj, 2016), but it was believed that, NE infection caused numerous changes to immunological structure of cytokines and toll-like receptors (Collier et al., 2008). Despite the fact that, a number of probiotics which have been extensively studied here and others in the poultry industry, yet there are many probiotics without clearly defining their mode of action. Therefore, the main objective of this study, was to evaluate the effect of Bacillus subtilis DSM 32315 probiotic and antibiotic (enramycin) on Clostridium perfringens-induced Necrotic enteritis on immunomodulators, nutrient transporters, distribution of bacterial population and functional diversity in broiler chickens.

\section{MATERIAL AND METHODS}

\section{Ethical approval}

The present study was approved by the Institutional Animal ethics Committee at the Northwest Agriculture and Forestry University (protocol number NWAFAC1008 Yangling, Shaanxi, China).

\section{Animals and Trial Design \\ Test strain information}

Bacillus subtilis DSM 32315 used in this study was provided by Evonik Nutrition and Care GmbH, (Hanau, Germany) throughout the experimental period, the product contained a spray-dried spore forming bacteria at a concentration of $2 \times 10^{9} \mathrm{CFU} / \mathrm{g}$, while AGP (Enramycin) was obtained from Wuhan Guangtu Technology Coop., Ltd. (China).

A total of 360 one-day-old Arbor Acre mixed sexed chickens were randomly assigned to three treatment groups (each one had ten cages of twelve birds). One group was supplemented with basal diet only; control $(\mathrm{CON})$; The second group was antibiotic group (AB) 
supplemented with basal diet supplemented with $5 \mathrm{mg} / \mathrm{kg}$ enramycin, challenged with $C$. perfringens; and the third group was probiotic group (PB) supplemented basal diet with $2 \times 10^{9} \mathrm{CFU} / \mathrm{g}$ Bacillus subtilis DSM 32315 , challenged with $C$. perfringens. The broiler chickens were kept in a closed, ventilated and wire-floor caged broiler house (100 cm long $\times 80 \mathrm{~cm}$ wide $\times 50 \mathrm{~cm}$ height $/$ cage) . The cages had a linear feeder at the front and a nipple drinker at the back to provide feed and water ad libitum throughout the experimental period. Thirty-three ${ }^{\mathrm{O}} \mathrm{C}$ room temperature was maintained for the first week, and then reduced by $3{ }^{\circ} \mathrm{C}$ per week until it reached $24{ }^{\circ} \mathrm{C}$. Light was provided 24 hour/day.

\section{Clostridium perfringens infection}

The $C$. perfringens challenge was carried out as previously described (Dahiya et al, 2007). C. perfringens type-A (CPA) (CVCC2030) was obtained from China Veterinary Culture Collection Center (CVCC52) of China Institute of Veterinary Drug Control (Beijing, China).The bacteria was cultured under anaerobic condition at $37{ }^{\circ} \mathrm{C}$ in peptone yeast broth overnight (Shoemaker and Pierson, 1976). The cultured medium was centrifuged at $6000 \mathrm{x} \mathrm{g}$ at $4^{\circ} \mathrm{C}$ for 10 minutes, and re-suspended in $0.01 \mathrm{M}$ Phosphate Buffered Saline (PBS). The concentration of $C$. perfringens was adjusted to $10^{8} \mathrm{CFU} / \mathrm{mL}$, and each chicken in the challenged groups was orally gavaged with $0.5 \mathrm{~mL}$ at day 1 of age, and $1 \mathrm{~mL}$ from day 14 to day 21 of age, once per day, to induce the NE infection.

\section{Tissue sample collection}

At each time of sample collection, one bird/pen and ten birds/treatment were randomly selected and euthanized for the intestinal tissue sample collection, and five samples were used for testing out of the ten collection. The intestinal tissue samples were collected at day 7 and day 21 post challenge (PC) ( 21 and 35 days of age) for cytokines and nutrient transporters mRNA expression and cecal samples were collected at 14, 21 and 35 days of age for qRT-PCR and at 21 and 35 days of age for cecal microbiota composition. The contents of the intestine from duodenum, jejunum and ileum were separated and squeezed out, and segments were rinsed with PBS, and mucosal scrapping from each segment (duodenum, jejunum and ileum) were collected for RNA extraction for cytokines and nutrients transporter genes expression. Cecal luminal contents were also collected for qRT-PCR and microbiota composition. All the samples were collected into an aseptic $2 \mathrm{~mL}$ tubes and frozen immediately in liquid nitrogen, later stored at $-80^{\circ} \mathrm{C}$ for further analysis.

\section{DNA Extraction and Cecal Bacterial Determination by Absolute qPCR}

The genomic bacterial DNA was extracted using 80 $\pm 10 \mathrm{mg}$ of cecal contents using a modified Cetyltrimethylammonium Ammonium Bromide (CTAB) method as described by Minas et al. (2011). However, the total DNA quantity and quality were determined using Nanodrop ${ }^{\circledR} \quad$ ND-2000 spectrophotometer (Thermo scientific, MA, USA), while the quality of the DNA was determined using agarose gel (1\%) electrophoresis. All DNA samples were diluted to $30 \mathrm{ng} / \mu \mathrm{L}$ and stored in $-20^{\circ} \mathrm{C}$ thereafter. The cecal abundance of Bifidobacterium bifidum, Pediococcus, Enterobacter, Lactobacillus salivarius Escherichia coli, and Clostridium perfringens were determined using SYBR Green I based absolute qPCR contained the specific primers for each gene (Table 1). The qPCR plasmid standard was prepared as previously described by Liu et al. (2017). The concentration of plasmid standard of the aforementioned bacteria was diluted to $20 \mathrm{ng} / \mu \mathrm{L}$, and then subjected to a serial of tenfold dilutions $\left(10^{-1} \sim 10^{-6}\right)$ to obtain the standard curve. The copy number of the diluted plasmid standard obtained were used and calculated as previously describe by Li et al. (2018). The abundance of the aforementioned bacteria in each sample with $30 \mathrm{ng}$ metagenomic DNA where calculated with the equation: $\mathrm{X} \log \left[\left(\mathrm{M}_{\mathrm{DNA}} / \mathrm{M}_{\mathrm{C}}\right) \times\right.$ $(\mathrm{C} 30 / 30) \times \mathrm{D}], \mathrm{M}_{\mathrm{DNA}}$ represented the weight of total DNA in the sample $(\mathrm{ng}) ; \mathrm{M}_{\mathrm{C}}$ represented the weight of the content used (g); C30 represented the copy number of 30ng metagenomic DNA (plug Ct values into the standard curve); where D represented the dilution ratio. The copy number of each bacterial population was calculated from the standard curves, and finally the population of the bacteria was expressed as $\log _{10} \mathrm{CFU} / \mathrm{g}$ content.

\section{RNA Isolation and Quantitative RT-PCR for relative expression}

The total RNA and complementary DNA from the mucosal scrapping were obtained using TRIzol Reagent following manufacturer's instruction (Invitrogen, Carlsbad, CA). Quantity and purity of RNA were determined using a Nanodrop ${ }^{\circledR}$ ND-2000 spectrophotometer (Thermo scientific, MA, USA), and RNA quality was assessed by Agarose gel (1\%) electrophoresis, the cDNA was synthesized from the total RNA using cDNA reverse transcription kit (TaKaRa, Dalian, China) according to manufacturer's instructions, as previously described by Li et al. (2018). A summary of the gene sequences forward and reverse primers used for PCR are shown in table 2. The average threshold cycle 
values for relative quantification after normalizing with $\beta$ actin were used for each target gene using $2^{-\Delta \Delta \mathrm{Ct}}$ method (Livak and Schmittgen, 2001).

\section{Metagenomic sequencing}

The total DNA from the cecal samples were extracted using QIAamp DNA Stool Mini Kit (QIAFEN, Germany), according to manufacturer's instructions, and then were eluted with double-distilled water and stored at $-20^{\circ} \mathrm{C}$ for further use. Ultrasonic genomic DNA was randomly disrupted, and purified by agarose gel electrophoresis. The sequencing linker was ligated, and the ligation product was separated by $2 \%$ agarose gel electrophoresis. The recovered product of the appropriate size was cut and amplified using qPCR and purified to obtain the final library; the DNA library was constructed and sequenced using illumina Hiseq 2500. To ensure high-quality reads, the raw image data obtained by sequencing were subjected to preliminary mass analysis, and second-generation sequencing data quality filtering were used to remove the low-quality and linker sequences (removal of adapter-containing reads; removal of $\mathrm{N}$-containing reads with a ratio greater than $10 \%$; remove low-quality reads mass value $\mathrm{Q} \leq 20$ bases account for more than $40 \%$ of the entire read. The final reads (Last HQ Clean Reads) and high-quality sequences were used for subsequent analysis. Default selection parameter: -id 0.90, id was similar ( $90 \%$ similarity). The software deduplicated all the Scaftigs assembled from each sample. Statistical summarization was carried out and the abundance table of the redundant genes was combined to perform functional abundance analysis. The putative amino acid sequence was aligned from the gene catalogue Kyoto Encyclopedia of Genes and Genomes (KEGG). The database KEGG Pathway divided the biological metabolic pathway into six categories named Metabolism, Genetic Information Processing, Environmental Information Processing, Cellular Processes, Organismal Systems, and Human Diseases; each of which was also classified into B, C, and $\mathrm{D}$ levels by the system. Among them, the B class used in this study currently included 43 seeds functions; the $\mathrm{C}$ class which was the metabolic pathway map; and the D class was the specific annotation information for each metabolic pathway map. The version of the KEGG database used in the current annotation was Released 76.0, October 1, 2015, and the comparison software used was BLAST+ (version: 2.2.29, parameter: -evalue 1e-5).

\section{Statistical analyses}

With the exception of 16S rRNA gene sequencing, all data were analyzed by one-way Analysis of Variance (ANOVA) using the General Linear Model (GLM) Procedure of Statistical Analysis System (SAS) (SAS Institute Inc. Base SAS ${ }^{\circledR}$ 9.4, 2015). Post-hoc Duncan's Multiple Range test was carried out with a P-value $<0.05$ as significant. Results were expressed as mean \pm Standard Error of the Mean (SEM).

Table 1. Primers for absolute qPCR analysis by $16 \mathrm{~S}$ rRNA

\begin{tabular}{llll}
\hline Target species & Amplicon size (bp) & Sequence (5'-3') ${ }^{\mathbf{1}}$ & References \\
\hline Bifidobacterium bifidum & 290 & $\begin{array}{l}\text { F: CCACCGTTACACCGGGAA } \\
\text { R: GGGTGGTAATGCCGGATG }\end{array}$ & Self-designed \\
\hline Lactobacillus salivarius & 108 & $\begin{array}{l}\text { F: CACCGCTACACATGGAG } \\
\text { R: AGCAGTAGGGAATCTTCCA }\end{array}$ & Self -designed \\
\hline Pediococcus & \multirow{2}{*}{$\begin{array}{l}\text { F: CACCGCTACACATGGAG } \\
\text { Enterobacter }\end{array}$} & R: AGCAGTAGGGAATCTTCCA & Heiling et al. (2002) \\
\hline Escherichia coli & 198 & F: ATTGACGTTACCCGCAGAAGAAGC & Walter et al. (2001) \\
\hline Rlostridium perfringens & 96 & F: CGGGTAACGTCAATGAGCAAA & Self-designed \\
\hline
\end{tabular}

${ }^{1}$ F: Forward, R: Reverse. 
Table 2. Oligonucleotide primers used for quantitative RT-PCR.

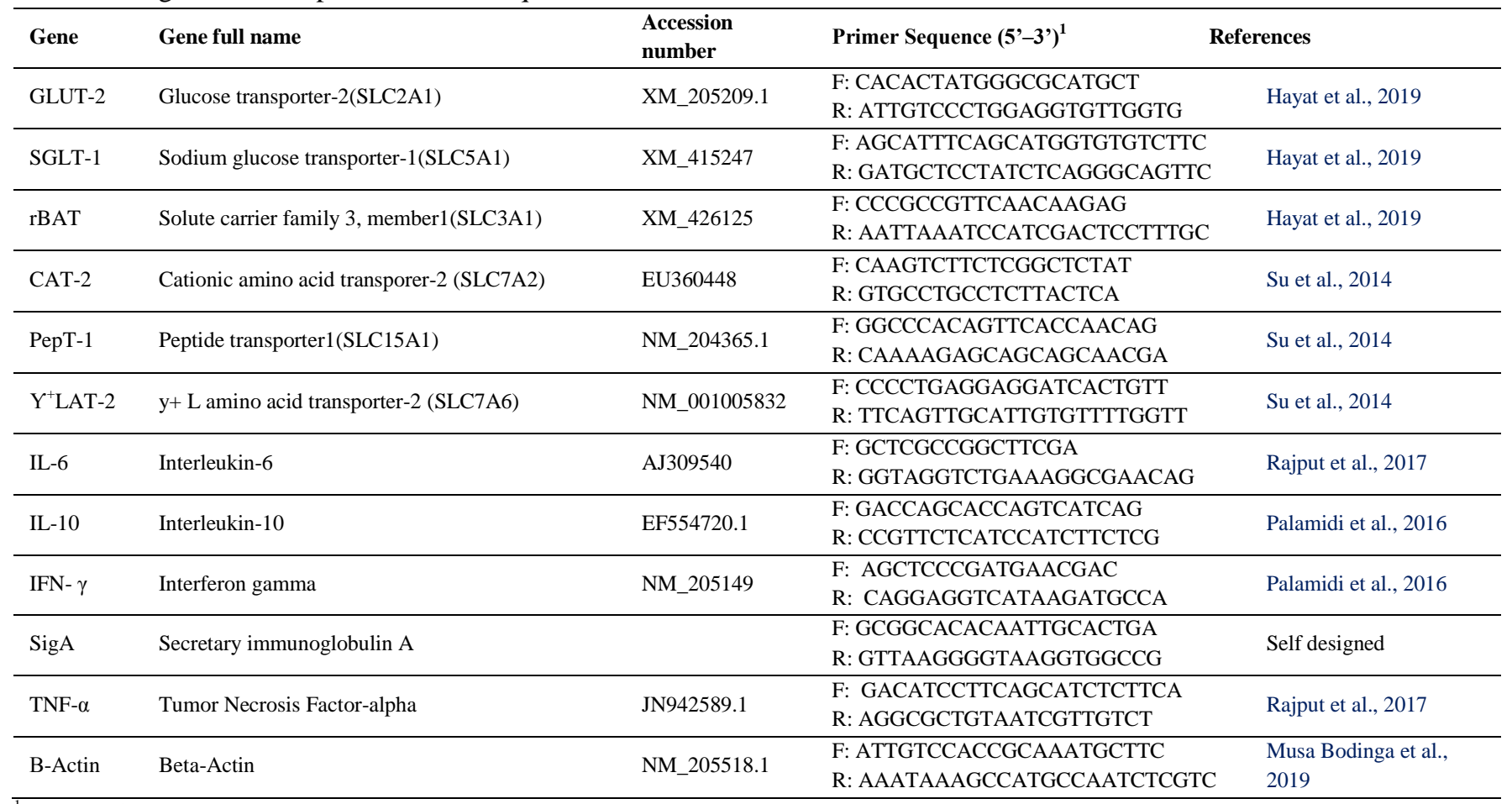

${ }^{\mathrm{T}} \mathrm{F}$ : Forward, R: Reverse.

\section{RESULTS}

\section{Data and sequencing}

Cecal chicken samples from Control, Antibiotic and Probiotic groups were freshly collected, and sent for sequencing. The total DNA was extracted using QIAamp DNA Stool Mini Kit (QIAFEN, Germany), and was eluted with $\mathrm{ddH}_{2} \mathrm{O}$ and stored at $-20^{\circ} \mathrm{C}$ for further use. Ultrasonic genomic DNA in the sample was randomly disrupted, and the target fragment was recovered and purified by agarose gel electrophoresis. The ligation product was separated using 2\% agarose gel electrophoresis, and the recovered product of the appropriate size was cut and amplified by PCR, and purified to obtain a final library. The constructed library was sequenced using Illumina $\mathrm{HI}$ sequence TM 2500. Illumina, in cooperation, San Diego, CA USA, A total of 776,294,600 higher quality classifiable reads were generated from all samples with the average of $129,328,433$ sequence per sample, and a maximum number of sequences of $143,723,136$, and a minimum of 122,474,100 (Table 3).

\section{Variation of cecal bacterial microbiome}

The sample richness and alpha diversity of the cecal microbiome of boiler chickens are shown in Table 4 . Alpha diversity was compared among the three fed-groups at twenty first and thirty fifth days of age respectively. The results revealed that the species richness of Chao1 and Ace indices were highest in AGP and PB, and lowest in CON group at both $21_{\mathrm{st}}$ and $35_{\mathrm{th}}$ days of the age.

\section{Bacterial taxonomic composition}

The bacterial compositions at the phylum level are presented in figure $1 \mathrm{a}$ and $1 \mathrm{~b}$ respectively. At $21_{\mathrm{st}}$ day of age, Firmicutes was the dominant microbiota in all the three fed-groups, $81.3 \%, 80.9 \%$ and $81.2 \%$ in $\mathrm{CON}, \mathrm{AB}$ and PB respectively, followed by proteobacteria, Actinobacteria as well as other unclassified group respectively with no significant variation between the groups (Figure 1a). However, at $35_{\text {th }}$ day of age, the dominant microbiota were likewise Firmicutes. Proteobacteria, and Actinobacteria with phylum Firmicutes were having the highest abundance in $\mathrm{AB}$ and PB fed-groups than in CON group, 73.3\%, 76.5\% and $77.3 \%$ (Figure 1b), while in addition to the three major phylum detected, $6.8 \%$ of Bacteroidetes were detected in PB fed group, nonetheless, observed decreased of $8 \%$, $4.4 \%$ and $3.9 \%$ of Firmicutes in $\mathrm{CON}, \mathrm{AB}$ and $\mathrm{PB}$ respectively, and increase in the relative taxa abundance of $3.1 \%, 2.1 \%$ and $0.5 \%$ of proteobacteria in $\mathrm{CON}, \mathrm{AB}$ and PB fed-groups respectively (Figure 1b). 
Three relative abundance and microbial functions

The B level of Kyoto Encyclopedia of Genes and Genomes (KEGG) and the orthologues variation for important microbial functions of the cecal microbiome of the three groups at $21_{\mathrm{st}}$ and $35_{\mathrm{th}}$ days of age were identified respectively (Figure $2 \mathrm{a}$ and $2 \mathrm{~b}$ ). Six orthologues pathways for the relative abundance of genes encoded in KEGG level B were considered such as translation, replication and repair, amino acid metabolism, carbohydrate metabolism, membrane transport, and vitamin metabolism co-factor (Figure 2a). At $21_{\text {st }}$ day of the age, the gut microbiota in CON group was richest in translation, replication and repair pathways, while $\mathrm{AB}$ fed-group showed enrichment in amino acid metabolism. It was also observed that gut microbiota was richest in pathways related to carbohydrate metabolism, and membrane transport in PB fed-group. Similarly, at $35_{\text {th }}$ day of age, PB fed-group maintained the highest enrichment in carbohydrate metabolism of cecal microbiota related pathways. However, membrane transport replication and repairs pathways were relatively richer in $\mathrm{AB}$ fed-group, while the CON group was richer in translation pathways. (Figure 2). The distribution of functional components of cecal microbiome $B$ level of KEGG classification pathways, each data represents ten chickens for each five samples from each group (a) at $21_{\text {st }}$ day of age; (b) 35 days of age; 21 and 35 days of age (day 7 and 21 post challenged). The three groups were control group $(\mathrm{CON})$; supplemented with basal diet only, antibiotic group (AB); basal diet supplemented with enramycin $(5 \mathrm{mg} / \mathrm{kg})$ and challenged with $C$. perfringens, probiotic group (PB); basal diet supplemented with B. subtilis DSM 32315 $\left(2 \times 10^{9} \mathrm{CFU} / \mathrm{g}\right)$ and challenged with $C$. perfringens.

\section{Cecal microbial populations detected by absolute qPCR}

The mean $\log _{10} 16 \mathrm{~S}$ rRNA gene copies/g of the cecal digesta for Bifidobacterium bifidum, Escherichia coli, Clostridium perfringens, Enterobacter, Lactobacillus salivarius and Pediococcus of broilers were detected at 14 , 21 and 35 days of the age which are shown in figure 3. At $14_{\text {th }}$ day of the age, the bacterial abundance of B. bifidum, Enterobacter, and $L$. salivarius were significantly higher $(\mathrm{P}<0.05)$ in $\mathrm{AB}$ and $\mathrm{PB}$, while relative abundance of $E$. coli was significantly $(\mathrm{P}<0.05)$ higher in $\mathrm{CON}$ group (Figure 3a). However, at $21_{\text {st }}$ day of the age, no significant difference $(\mathrm{P}>0.05)$ in the populations of $C$. perfringens, B. bifidum and Pediococcus, was detected, but the relative abundance of Enterobacter and $L$. salivarius were significantly higher in $\mathrm{AB}$ and $\mathrm{PB}$ group, while relative abundance of $E$. coli was significantly higher in $\mathrm{CON}$ and PB fed-group than in their counterpart groups (Figure $3 b$ ). Similarly, at $35_{\text {th }}$ day of the age, no significant difference was observed in the cecal abundance in Pediococcus and C. perfringens, whereby the abundance of B. bifidum, Enterobacter and $L$. salivarius were significantly higher in $\mathrm{AB}$ and $\mathrm{PB}$ than in $\mathrm{CON}$ fed-group.

\section{Sugars, amino acids and peptides transporters mRNA genes expression}

The mRNA expression levels of nutrient transporters (Monosaccharides) such as Glucose transporter- 2 (GLUT2), Sodium glucose transporter-1 (SGLT-1) and (Solute carrier family 3, member-1 (rBAT) of the intestinal mucosa from duodenum, jejunum and ileum at $21_{\mathrm{st}}$ and $35_{\text {th }}$ days of the age are presented in figure 4 . In the duodenum, at $21_{\mathrm{st}}$ day of age, mRNA expressions of GLUT-2 were significantly $(\mathrm{P}<0.05)$ higher in $\mathrm{PB}$ and $\mathrm{AB}$, while SGLT-1 and $\mathrm{rBAT}$ significantly showed high expression in $\mathrm{PB}$ than in $\mathrm{CON}$ and $\mathrm{AB}$ fed-groups (Figure 4a). Similarly, at $35_{\text {th }}$ day of age, PB fed-group showed significantly $(\mathrm{P}<0.05)$ higher expression of GLUT-2 and SGLT-1, whereas, rBAT was significantly higher in $\mathrm{AB}$ and $\mathrm{PB}$ than in CON fed-group (Figure $4 \mathrm{~b}$ ). Likewise, in jejunum, $\mathrm{AB}$ and $\mathrm{PB}$ showed high expression of GLUT-2 and rBAT, while, at $35_{\text {th }}$ day of age, SGLT-1 and GLUT-2 significantly showed down regulation with the highest expression in $\mathrm{PB}$ than in $\mathrm{CON}$ and $\mathrm{AB}$ fed-groups (Figure $4 d)$. However, in ileum, at $21_{\text {st }}$ and $35_{\text {th }}$ days of age, GLUT -2 and $\mathrm{rBAT}$ were significantly $(\mathrm{P}<0.05)$ expressed in $\mathrm{PB}$ than in $\mathrm{AB}$ and $\mathrm{CON}$ group (Figure $4 \mathrm{e}$ ).

\section{The amino acids and peptides mRNA genes expression \\ The amino acid and peptide transporters;} Oligopeptide tansporter-1(PepT-1), L amino acid transporter-2 (LAT-2) and Cationic amino acid transporter-2 (CAT-2) from duodenum, jejunum and ileum at $21_{\mathrm{st}}$ and $35_{\text {th }}$ days of age are presented in figure 5 . Results showed the expression of LAT-2 at $21_{\text {st }}$ and $35_{\text {th }}$ days of age in duodenum, and CAT-2 at $35_{\text {th }}$ days was significantly $(\mathrm{P}<0.05)$ higher in $\mathrm{AB}$ and $\mathrm{PB}$ fed-groups. Also, $\mathrm{PB}$ showed significantly $(\mathrm{P}<0.05)$ higher expression of PepT-1 than in $\mathrm{AB}$, while CON group shows the lowest expression (Figure $5 \mathrm{a}$ and $5 \mathrm{~b}$ ). In jejunum, at $21_{\mathrm{st}}$ day of age, groups fed $\mathrm{AB}$ and $\mathrm{PB}$ significantly $(\mathrm{P}<0.05)$ showed a higher expression of PepT-1 and LAT-2, while CAT-2 at $21_{\text {st }}$ days of age and PepT-1 at $35_{\text {th }}$ day of age, were significantly $(\mathrm{P}<0.05)$ higher in $\mathrm{AB}$ than in $\mathrm{PB}$ fedgroup, with the lowest expression in $\mathrm{CON}$ group (Figure 
5c). Similarly, expression of CAT-2 was significantly (P < 0.05 ) higher in $\mathrm{AB}$ and $\mathrm{PB}$ than in $\mathrm{CON}$ group (Figure $5 \mathrm{~d}$ ). In Ileum at $21_{\text {st }}$ day of age, only LAT-2 showed substantial difference with $\mathrm{AB}$ fed-group having the highest expression (figure 5e), On the other hand, at $35_{\text {th }}$ day of age, LAT-2 and CAT-2 showed significantly (P < 0.05) higher expression in $A B$ and $P B$ than in the $C O N$ group, while expression of PepT-1 was meaningfully ( $\mathrm{P}<$ 0.05 ) higher in $\mathrm{PB}$ than $\mathrm{AB}$ with the lowest expression in CON group (Figure 5f).

\section{The Cytokines mRNA genes Expression}

There were also some changes in mRNA expression of proinflammatory cytokines of interleukin-6, tumor necrosis factor alpha and interferon gamma from duodenum, jejunum and ileum of the three groups at $21_{\mathrm{st}}$ and $35_{\text {th }}$ days of the age (Figure 6). In duodenum at $21_{\text {st }}$ day of age (figure 6a), expression of IL-6, TNF- $\alpha$ and IFN- $\gamma$, and at $35_{\text {th }}$ day of age (figure $6 \mathrm{~b}$ ), IL-6 and TNF- $\alpha$ were significantly higher compared to $\mathrm{AB}$ and $\mathrm{PB}$ challenged groups. Also, in jejunum, at $21_{\text {st }}$ day of age (figure 6c), IL-6, TNF- $\alpha$, IFN- $\gamma$ and at $35_{\text {th }}$ day of age (figure $6 \mathrm{~d}$ ), TNF- $\alpha$ and IFN- $\gamma$ were significantly $(\mathrm{P}<0.05)$ higher in $\mathrm{CON}$ than in $\mathrm{AB}$ and $\mathrm{PB}$. Similar trends were also observed in ileum at $21_{\text {st }}$ day of age (figure 6e), and $35_{\text {th }}$ day of age (Figure 6f). The mRNA expression level of anti-inflammatory cytokine of IL-10, and mucosal secretory immunoglobulin $A$ at $21_{\mathrm{st}}$ and $35_{\mathrm{th}}$ days of the age were measured. At $21_{\mathrm{st}}$ day of age, $\mathrm{AB}$ and PB fedgroup considerably $(\mathrm{P}<0.05)$ indicated higher expression of SigA than in CON group (figure $7 \mathrm{a}$ ), while at $35_{\text {th }}$ day of age, $\mathrm{PB}$ fed-group showed significantly $(\mathrm{P}<0.05)$ higher expression of IL-10, and SigA than in AB fedgroup, and the lowest expression was in CON group (Figure 7b). In jejunum, at $21_{\text {st }}$ day of age, SigA was upregulated in $\mathrm{AB}$ than in $\mathrm{PB}$ and $\mathrm{CON}$ fed-group, whereas expression of IL-10 was meaningfully $(\mathrm{P}<0.05)$ upregulated in $\mathrm{AB}$ and $\mathrm{PB}$ than in $\mathrm{CON}$ fed-group (Figure $7 \mathrm{c})$. However, at $35_{\text {th }}$ day of age, IL-10 was upregulated in $\mathrm{PB}$ than in $\mathrm{CON}$, while SigA was upregulated in $\mathrm{AB}$ than in CON group (Figure $7 \mathrm{~d}$ ). Similarly, in ileum at $21_{\mathrm{st}}$ day of age, $\mathrm{AB}$ and $\mathrm{PB}$ showed notably $(\mathrm{P}<0.05)$ high expression of IL-10 and SigA than in CON (Figure 7e). Similarly, at $35_{\text {th }}$ day of age, expression of SigA in PB fedgroup was substantially $(\mathrm{P}<0.05)$ up-regulated than in $A B$ and $\mathrm{CON}$ fed-groups. Nonetheless, the changes in mRNA expression of proinflammatory cytokines of IL-10 in $\mathrm{AB}$ and PB were up-regulated than in CON group (Figure 7f). a

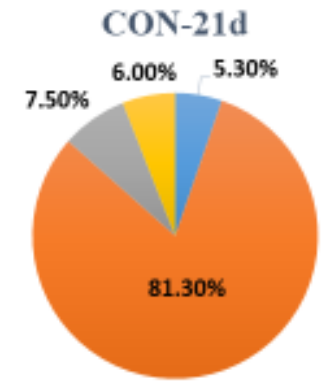

b

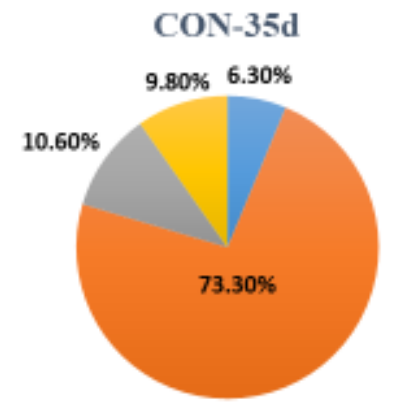

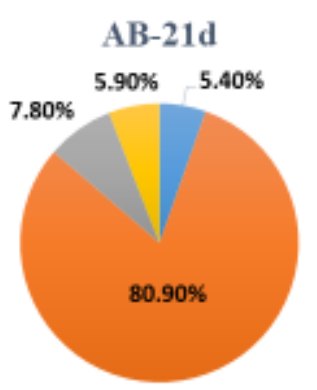

$A B-35 d$

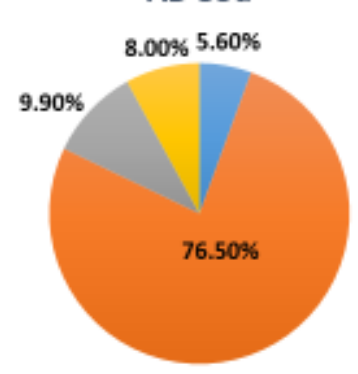

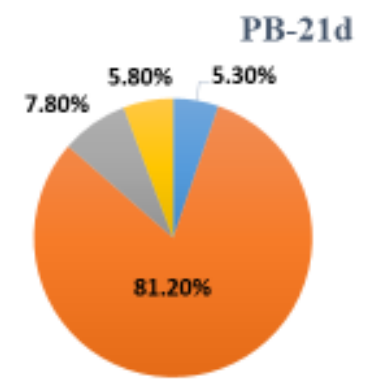

PB-35d

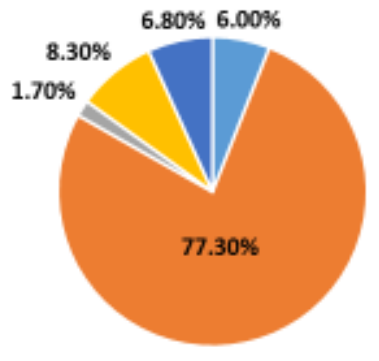

Actinobacteria

Firmicutes

Eroteobacteria

Others
= Actinobacteria

= Firmicutes

= Proteobacteria

= Others

- Bacteroides

Figure 1. Cecal bacterial composition of broiler chickens. Relative taxa abundance (\%), a: at 21 days of age and; b: at 35 days of age; 21 and 35 days of age means (day 7 and 21 post challenged respectively). The three groups contained: CON: control group supplemented with basal diet only; $\mathrm{AB}$ : antibiotic group (enramycin $5 \mathrm{mg} / \mathrm{kg}$ ) challenged with Clostridium perfringens; PB: probiotic group contained Bacillus subtilis $\left(2 \times 10^{9} \mathrm{CFU} / \mathrm{g}\right)$ challenged with Clostridium perfringens 


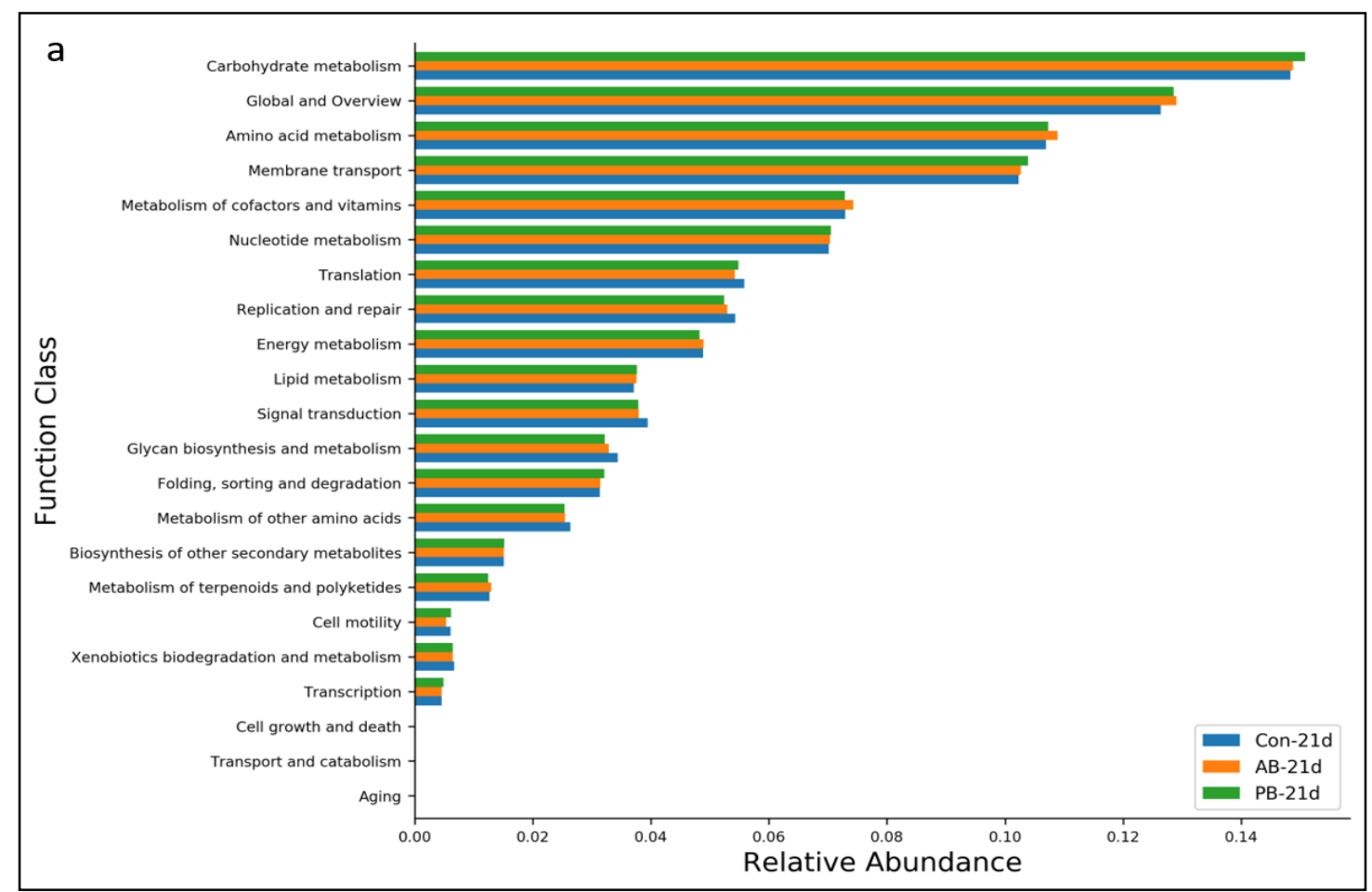

Figure 2a. Distribution of functional components of cecal microbiome B level of Kyoto Encyclopedia of Genes and Genomes (KEGG) classification pathways. Each data represents ten chickens for each five samples from each group; at 21 days of age means (day 7 post challenged). The three groups contained $\mathrm{CON}$ : control group supplemented with basal diet only; antibiotic group (AB): basal diet supplemented with (enramycin $5 \mathrm{mg} / \mathrm{kg}$ ) challenged with Clostridium perfringens; probiotic group (PB): basal diet supplemented with Bacillus subtilis DSM 32315 (2x10 $\left.0^{9} \mathrm{CFU} / \mathrm{g}\right)$ challenged with Clostridium perfringens

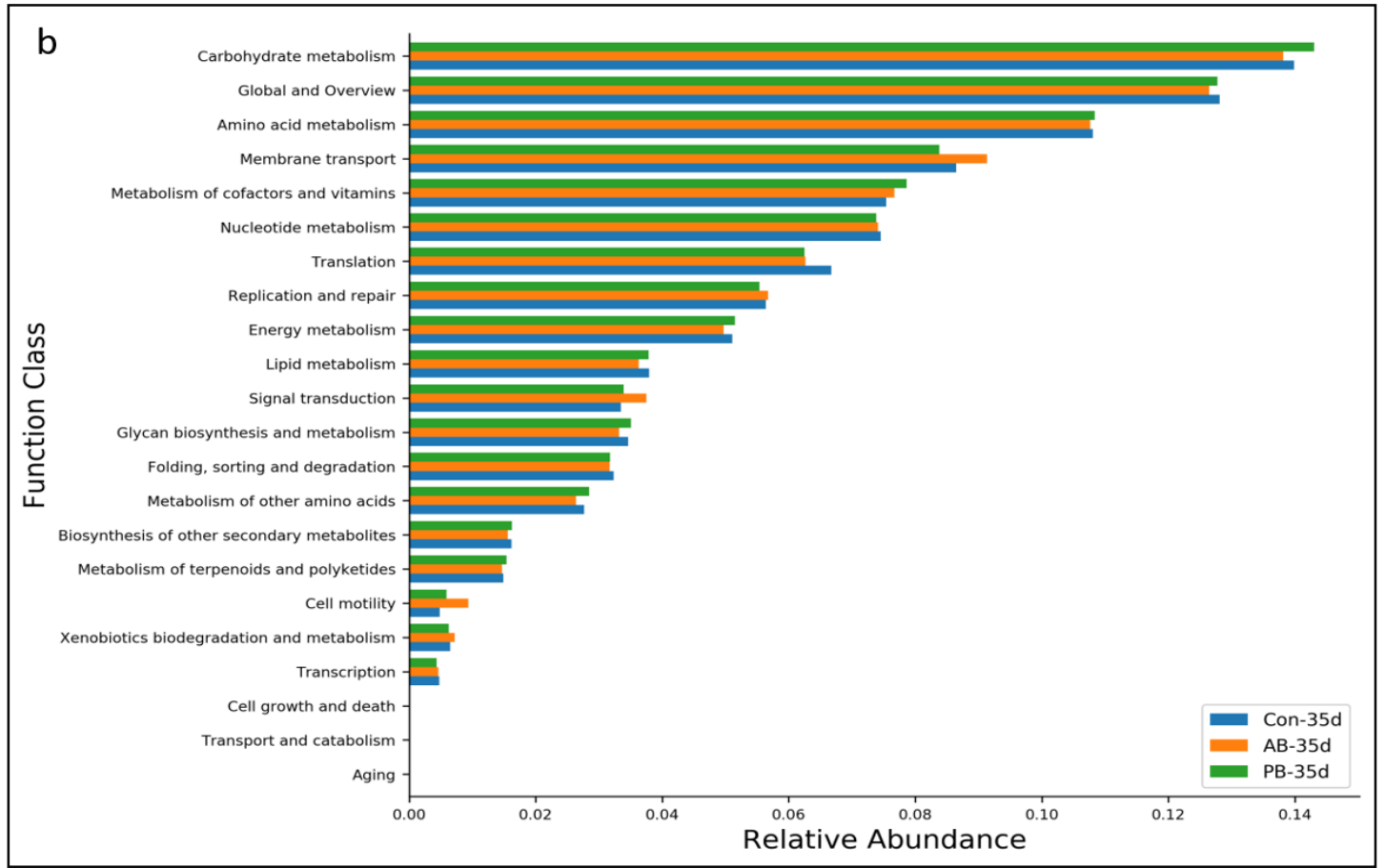

Figure 2b. Distribution of functional components of cecal microbiome B level of Kyoto Encyclopedia of Genes and Genomes (KEGG) classification pathways. Each data represents ten chickens for each five samples from each group; at 35 days of age means (day 21 post challenged). The three groups contained $\mathrm{CON}$ : control group supplemented with basal diet only; antibiotic group (AB): basal diet supplemented with (enramycin $5 \mathrm{mg} / \mathrm{kg}$ ) challenged with Clostridium perfringens; probiotic group (PB): basal diet supplemented with Bacillus subtilis DSM 32315 (2×109 CFU/g) challenged with Clostridium perfringens 


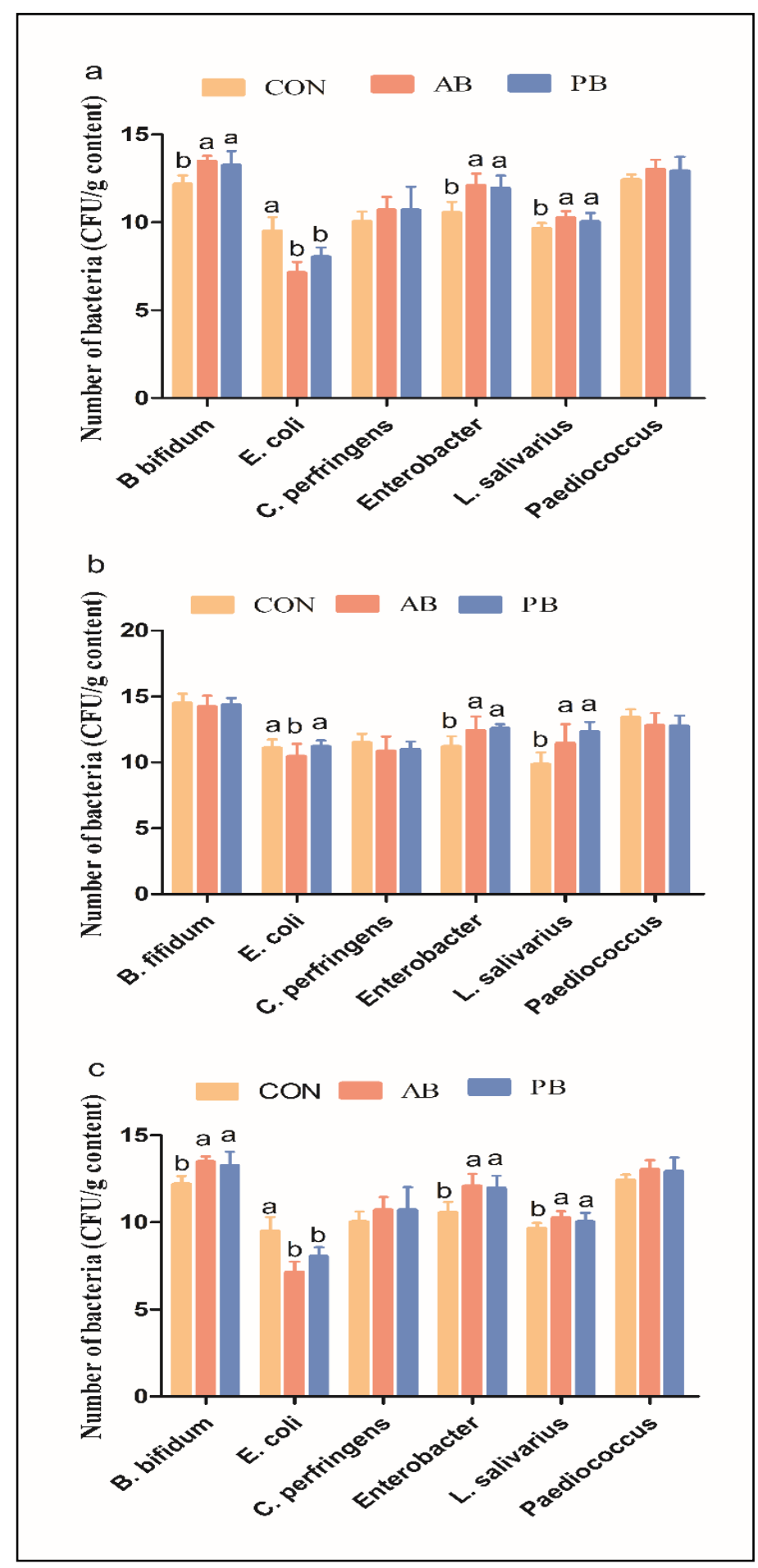

Figure 3. Composition of cecal microbiome number of $16 \mathrm{~S}$ rRNA gene copies broilers from three groups (a); at 14 days of age; (b); at 21 days of age (c); at 35 days of age; 14 days of age (before challenge); 21 days of age (7 days after challenged); and 35 days of age (21 days after challenged). The three groups are CON: control group supplemented with basal diet only; antibiotic group ( $\mathrm{AB}$ ): basal diet supplemented with; (enramycin $5 \mathrm{mg} / \mathrm{kg}$ ) challenged with Clostridium perfringens; probiotics group (PB): basal diet supplemented with Bacillus subtilis $\left(2 \times 10^{9} \mathrm{CFU} / \mathrm{g}\right)$ challenged with Clostridium perfringens, each data represents five replicates intestinal cecal samples for each group. The error bars indicate the standard error of the mean. Data was presented as $\log 10 \mathrm{CFU} / \mathrm{g}$ cecal content. a-c Means with different letters are significantly different $(\mathrm{P}<0.05)$. 


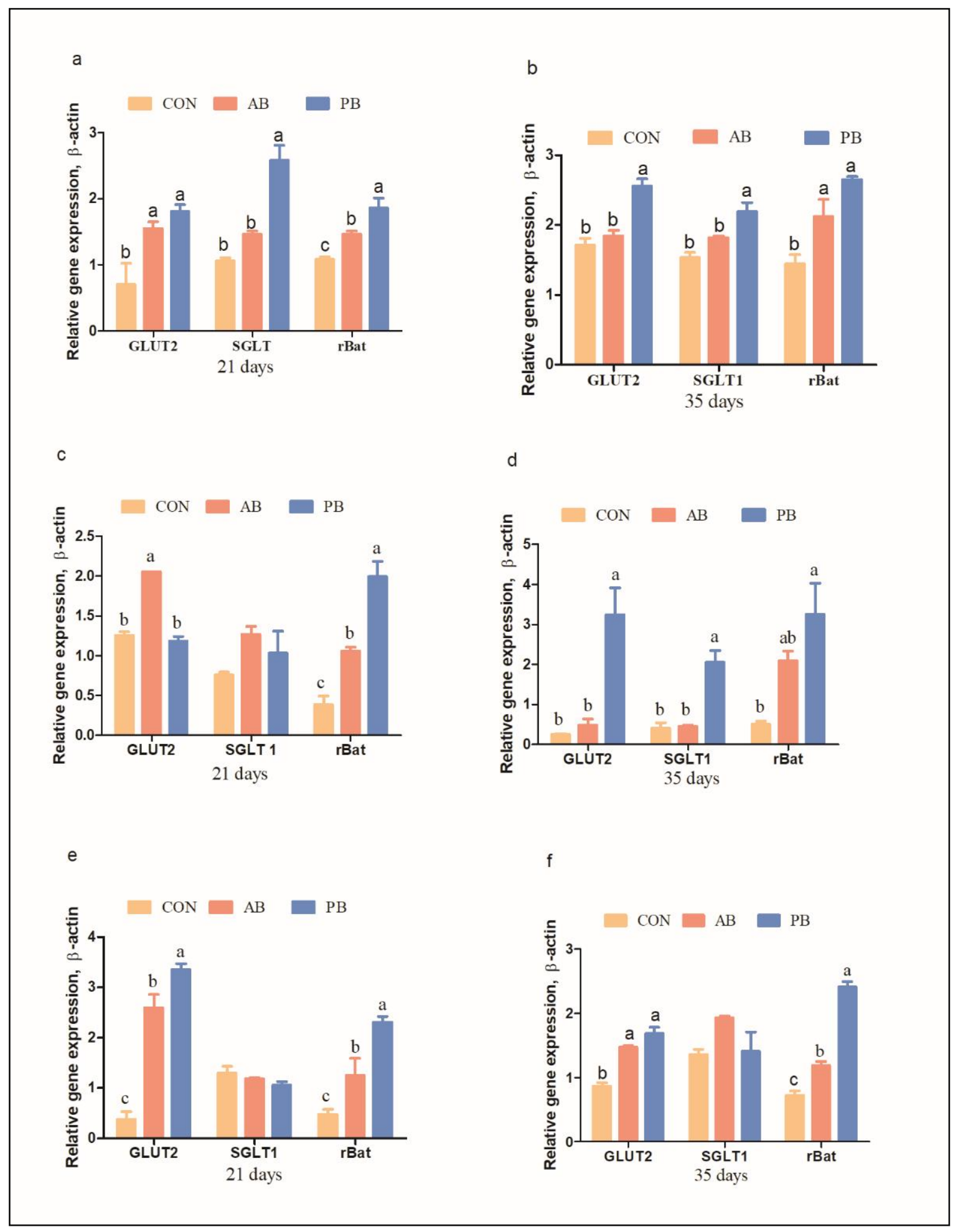

Figure 4. Relative mRNA expression levels of sugars transporters-related genes of the intestinal mucosa of broiler from duodenum, (Figure 4a and 4b) jejunum (Figure 4b and 4c) and ileum (Figure 4E and 4f) at 21 and 35 days of age, 21 and 35 days of age means (d 7 and d 21 post challenged). The three groups contained CON: control group supplemented with basal diet only; antibiotic group ( $\mathrm{AB}$ ): basal diet supplemented with; (enramycin $5 \mathrm{mg} / \mathrm{kg}$ ) challenged with Clostridium perfringens; probiotic group (PB): basal diet supplemented with Bacillus subtilis $\left(2 \times 10^{9} \mathrm{CFU} / \mathrm{g}\right)$ challenged with Clostridium perfringens, GLUT-2= glucose transporter-2, SGLT1= sodium glucose transporter-1, rBAT = Solute carrier family 3, member1 Data are the means \pm SEM of five chicks in each group. a-c Means with different letters are significantly different $(\mathrm{P}<0.05)$ 


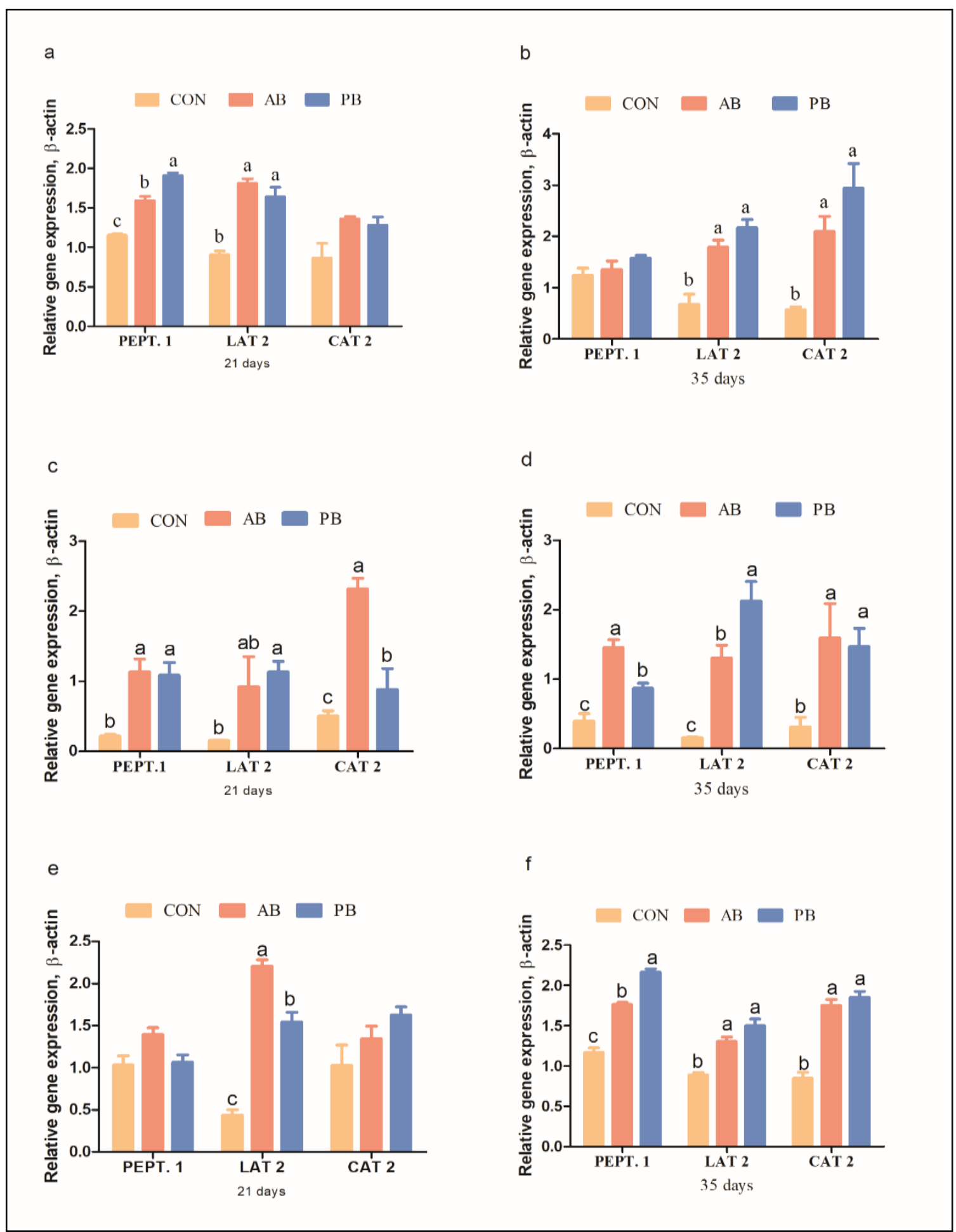

Figure 5. Relative mRNA expression levels of amino acid and peptide transporter related-genes of the intestinal mucosa of broiler from duodenum (Figure 5a and 5b), jejunum (Figure 5c and 5d) and ileum (Figure 5e and 5f) at 21 and 35 days of age, 21 and 35 days of age means ( 7 and d 21 post challenged). The three groups contained CON: control group supplemented with basal diet only; antibiotic group ( $\mathrm{AB}$ ): basal diet supplemented with; (enramycin $5 \mathrm{mg} / \mathrm{kg}$ ) challenged with Clostridium perfringens; probiotics group (PB): basal diet supplemented with Bacillus subtilis $\left(2 \times 10^{9} \mathrm{CFU} / \mathrm{g}\right)$ challenged with Clostridium perfringens, CAT-2 = cationic amino acids transporter-2; PepT-1= peptide transporter- $1, \mathrm{Y}^{+} \mathrm{LAT}-2=$ amino acid transporter- 2 . Data are the means \pm SEM of five chicks in each group. a-c Means with different letters are significantly different $(\mathrm{P}<0.05)$. 


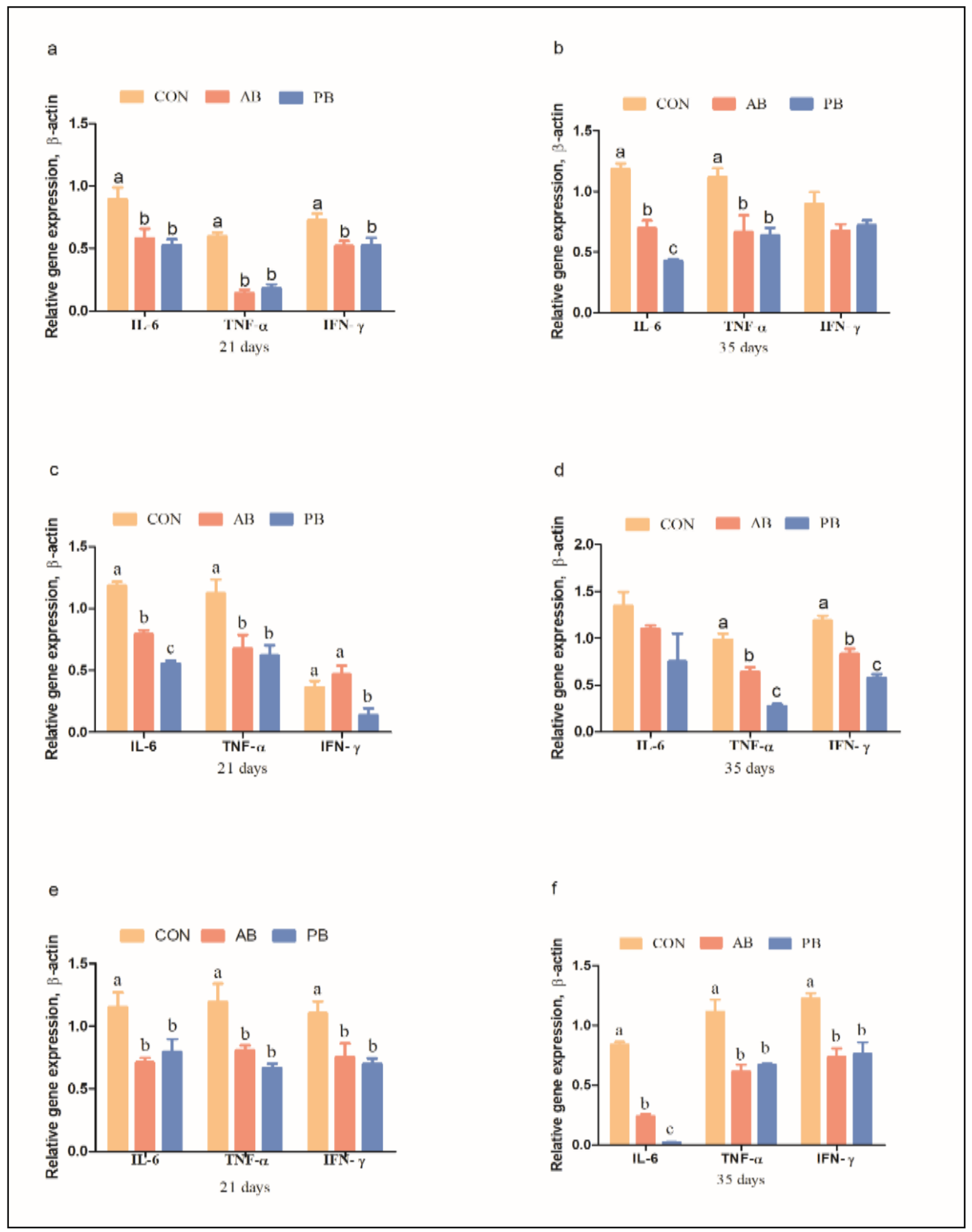

Figure 6. Relative mRNA expression levels of cytokine-related-genes of the intestinal mucosa of broiler from duodenum (Figure 6a and 6b), jejunum (Figure 6c and 6d) and ileum (figure 6e and 8f) at 21 and 35 days of age, 21 and 35 days of age means ( 7 and $\mathrm{d} 21$ post challenged). The three groups are contained CON: control group supplemented with basal diet only; antibiotic group ( $\mathrm{AB}$ ): basal diet supplemented with; (enramycin $5 \mathrm{mg} / \mathrm{kg}$ ) challenged with Clostridium perfringens; probiotic group (PB): basal diet supplemented with Bacillus subtilis $\left(2 \times 10^{9} \mathrm{CFU} / \mathrm{g}\right)$ challenged with Clostridium perfringens, IL- $6=$ interleukin 6; TNF- $\alpha=$ Tumor necrotic factor alpha; IFN- $\gamma=$ Interferon gamma. Data are the means \pm SEM of five chicks in each group. a-c Means with different letters are significantly different $(\mathrm{P}<0.05)$. 

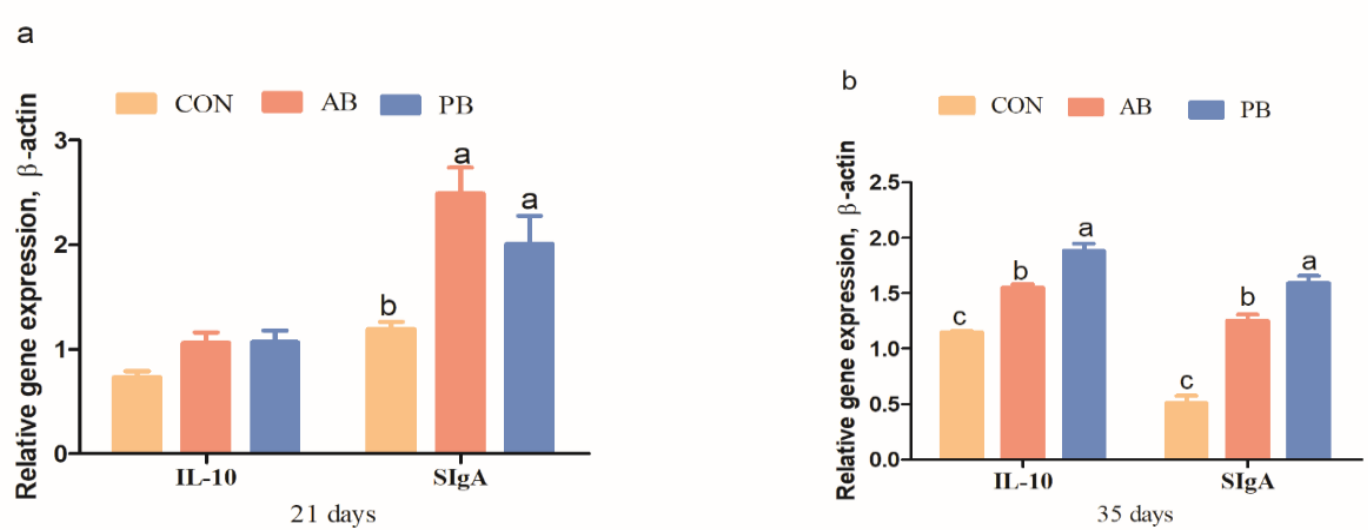

c
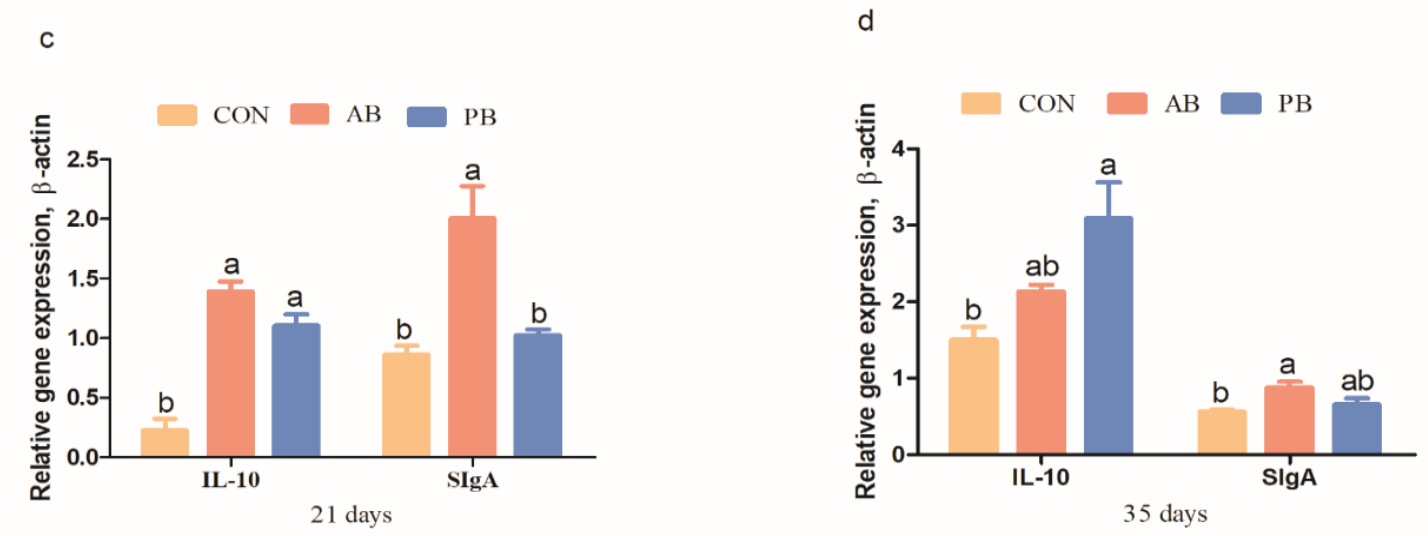

e

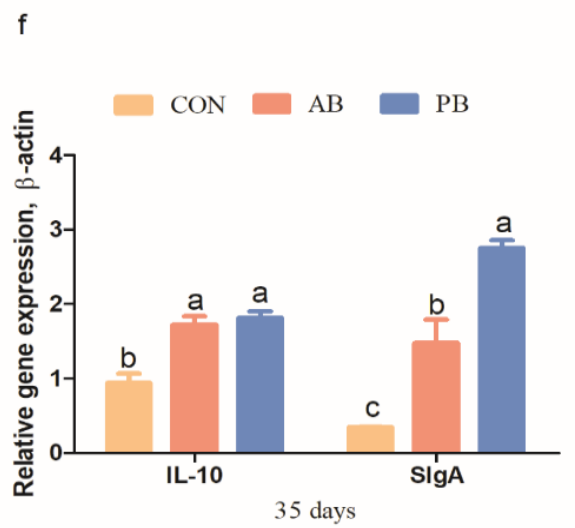

Figure 7. Relative mRNA expression levels of cytokine-related-genes in the intestinal mucosa of broiler from duodenum, (Figure 7a and 7b) jejunum (Figure 7c and 7d) and ileum (Figure 7e and 7f) at 21 and 35 days of age,21 and 35 days of age means (d 7 and d 21 post challenged). The three groups contained; CON: control group supplemented with basal diet only; antibiotic group (AB): basal diet supplemented with (enramycin $5 \mathrm{mg} / \mathrm{kg}$ ) challenged with Clostridium perfringens; probiotic group: (PB): basal diet supplemented with Bacillus subtilis $\left(2 \times 10^{9} \mathrm{CFU} / \mathrm{g}\right)$ challenged with Clostridium perfringens, IL-10= Interleukin 10; SigA= Secretory immunoglobulin A. Data are the means \pm SEM of five chicks in each group. a-c Means with different letters are significantly different $(\mathrm{P}<0.05)$. 
Bodinga et al., 2020

Table 3. Metagenome Illumina HI Sequencing raw and validated data statistics

\begin{tabular}{|c|c|c|c|c|}
\hline Groups & Total length (read) & Total base (bp) & Q20Base (\%) & Q30 Base (\%) \\
\hline Control 21d (Raw data) & 143723136 & 21558470400 & 95.82 & 90.84 \\
\hline (Validated data) & 137267732 & 20095347393 & 97.90 & 93.80 \\
\hline Antibiotic 21d (Raw data) & 124568192 & 18685228800 & 96.24 & 91.38 \\
\hline (Validated data) & 120150374 & 17579482737 & 97.94 & 93.89 \\
\hline Probiotic 21d (Raw data) & 126434430 & 18965164500 & 96.12 & 91.14 \\
\hline (Validated data) & 121778776 & 17822523973 & 97.87 & 93.71 \\
\hline Control 35d (Raw data) & 133089518 & 19963427700 & 96.21 & 91.18 \\
\hline (Validated data) & 128706256 & 18818324785 & 97.82 & 93.60 \\
\hline Antibiotic 35d (Raw data) & 126005224 & 18900783600 & 96.34 & 91.85 \\
\hline (Validated data) & 120660598 & 17707723742 & 98.19 & 94.49 \\
\hline Probiotic 35d (Raw data) & 122474100 & 18371115000 & 96.90 & 92.65 \\
\hline (Validated data) & 118742952 & 17442437811 & 98.27 & 94.68 \\
\hline
\end{tabular}

Table 4. Alpha diversity indices of the cecal microbiome of broiler chickens

\begin{tabular}{lcccccc}
\hline Groups & Number of reads & Chao1 & Ace & $\begin{array}{c}\text { Observed } \\
\text { species }\end{array}$ & Shannon & Simpson \\
\hline CON (21d) & 54981879 & 3837.72 & 3798.27 & 3715 & 4.252 & 0.86 \\
AB (21d) & 63691912 & 3954.03 & 3933.65 & 3880 & 4.189 & 0.85 \\
PB (21d) & 58508325 & 3922.09 & 3898.63 & 3844 & 4.205 & 0.84 \\
CON (35d) & 52962927 & 3994.97 & 3979.22 & 3917 & 4.304 & 0.83 \\
AB (35d) & 63280909 & 4065.55 & 4059.32 & 4002 & 4.455 & 0.85 \\
PB (35d) & 56346246 & 4060.63 & 4026.71 & 3947 & 4.309 & 0.84 \\
\hline
\end{tabular}

CON: control group supplemented with basal diet only; AB: antibiotic group supplemented with basal diet and enramycin $(5 \mathrm{mg} / \mathrm{kg})$ challenged with Clostridium perfringens; $\mathrm{PB}$ : probiotics group supplemented with basal diet and Bacillus subtilis $\left(2 \times 10^{9} \mathrm{CFU} / \mathrm{g}\right)$ challenged with Clostridium perfringens

\section{DISCUSSION}

Previous studies showed that pathogenic strains of $C$. perfringens can cause $\mathrm{NE}$ that disrupts, and lead to significant shift in the normal structure of gut microbiome in broiler chickens (Stanley et al., 2012; Mountzouris et al., 2015). Similarly, it was revealed that gut microbiome can provide the host with nutrients exchange, modulation of immune system and exclusion of pathogens, which had great impact on metabolic reactions (Binek et al., 2012). It was also revealed that, inclusion of $B$. subtilis strains probiotics in broiler diet could improve gut health, in the production of antimicrobial peptides and alteration of gut microbiome (Knap et al., 2011; Lee et al., 2011). Likewise, the use of in feed antibiotics were believed effective in mediating and decreasing the number of gut pathogenic bacteria in animals and humans (Dibner and Richards, 2005). Infeed antibiotics also proved an effective way to prevent animals from diseases, enhance feed efficiency, and to improve animal performance (Hooge et al., 2003; Kamran et al., 2013). Various species of Bacillus genus were known in producing bacteriocins and antimicrobial peptides ( Lee et al., 2011; Cochrane and Vederas, 2014; Park and Kim, 2014). B. subtilis SP6 showed an anti $C$. perfringens effect in vitro (Teo and Tan, 2005). The results of present study demonstrated that supplementation of $B$. subtilis DSM 32315 at $2 \times 10^{9}$ and antibiotic, enramycin at the dose of $5 \mathrm{mg} / \mathrm{kg}$ relatively altered the gut microbial diversity and functions of broiler chickens at $21_{\mathrm{st}}$ and $35_{\mathrm{th}}$ days of age as compared to the control group. This could be as a result of the early and continuous supplementation of $B$. subtilis probiotic from 1 to 42 days of age for the feeding period, which could probably mediate the beneficial effect of the gut microbiota through competitive exclusion (CE) in chickens by colonization and modulation of pathogens, while restoring the normalcy and integrity of gut ecosystem as well as the effect of the antibiotic administered to the chicken. Previous studies confirmed that several strains of $B$. subtilis have antagonistic activities against $C$. perfringens in vitro (Martaet al., 2014; Cochrane and Vederas, 2016). Similarly, the results of this 
study disclosed that $\mathrm{AB}$ and $\mathrm{PB}$ challenged groups had the highest percentage of population of dominant taxa such as Firmicutes, Proteobacteria and other bacterial groups at 35 days of age. Likewise, we observed a unique group of "Bacteroidetes" (6.8\%) in PB fed group, the dominant cecal microbiome composition obtained in this study was contrary to study of Xiao et al. (2017), that reported Bacteroidetes as the dominant bacterial group which could be to the fact that intestinal microbiome composition could be affected by many factors like surrounding environment, dietary supplementation, and pathological condition (Xiao et al., 2017). Firmicutes and Bacteroidetes were important gut microbiota in broiler that function in energy production and metabolism, specifically in microbial fermentation and starch digestion (Shaufi et al., 2015). Bacteroidetes primarily functioned in the formation of potential toxins via putrefaction that leads to increase $\mathrm{pH}$ of the intestinal contents which is of beneficial to the gut health against acid-sensitive pathogens (Apajalahti, 2005). Other species such as, B. salanitronisan which are inhabitant of chickens' cecum was well known for its ability in aiding further digestion of food by making the nutrients available to the host (Gronow et al., 2011). Also, with regards to $16 \mathrm{~S}$ rRNA sequences, B. bifidum, E. coli, $C$. perfringens, $L$. salivarius Enterobacter, and Pediococcus, the cecal contents, revealed significantly ( $\mathrm{P}$ $<0.05$ ) higher relative abundance in $\mathrm{AB}$ and $\mathrm{PB}$ fed groups, with suggestively higher population of E. coli in CON group without any supplementation. The higher relative abundance of $L$. salivarius and B. bifidum in PB fed-group could be attributed to their tolerance against $C$. perfringens infection. Alike results were found by Pyoung et al. (2007) who isolated several Lactobacillus and Bifidobacterium from pig gut that had antagonistic action against C. perfringens. Teo and Tan (2007) reported higher amount of Lactobacillus and Bifidobacterium from ileum of chickens supplemented with B. subtilis PB6. Similarly, Gilbert et al. (2008) observed a substantial increase in Lactobacillus abundance in the ilea and cecum of chickens following by $B$. subtilis C-3104 supplementation. Stanley et al. (2014) and Jeong and Kim (2015) reported that genus Lactobacillus in chickens' gut was predominant, and did not disturb the following $C$. perfringens infection. However, Lactobacillus was associated with reduction of intestinal inflammation and enhanced immunological barrier functions in broilers (Chen et al., 2012). Nevertheless, in this study, statistically no significant difference in the cecal population of $C$. perfringens either in supplemented groups or in the CON group fed basal diet only. This could signify that supplementation of either $\mathrm{AB}$ or $\mathrm{PB}$ directly or indirectly minimizes the proliferation of gut pathogens. More so, corresponding results were also obtained by Barbosa et al. (2005) and Teo and Tan (2005) who recognized B. subtilis and $B$. licheniformis as antagonistic species against $C$. perfringens infections. Likewise, in the present study, six enriched KEGG orthologues markers related to replication and repair, translation, amino acids metabolism, vitamin metabolism cofactor, membrane transport, and carbohydrate metabolism were considered. The CON group indicated enrichment in translation related pathways compared to $\mathrm{AB}$ and $\mathrm{PB}$ challenged groups. This could be attributed to the fact that $\mathrm{AB}$ and $\mathrm{PB}$ fed groups were challenged with $C$. perfringens which meant to induce NE, whereas, the subclinical form of the disease is characterized by necrosis, inflammation, pseudomembrane and mucosal hemorrhages (Wielen, 2000). Increase in carbohydrates metabolism related pathways in PB fed-group could be attributed to the high density of the commensals bacteria in the gut, in the sense that, many gut bacteria can additionally hydrolyze indigestible carbohydrate of polysaccharides, oligosaccharides and disaccharides to their compositional sugars, which later be fermented by gut bacteria, producing short chain fatty acids which can be utilized as energy source by the host (Hooper et al., 2002; Tellez et al., 2006). The high relative abundance of Lactobacillus spp. and Bifidobacterium from both $\mathrm{AB}$ and $\mathrm{PB}$ fed-groups could influence carbohydrate metabolism, and release energy into the host.

\section{CONCLUSION}

In conclusion, $C$. perfringens challenged broilers, with supplementation of AGP enramycin at the dose of $5 \mathrm{mg} / \mathrm{kg}$ or probiotic B. subtilis DSM 32315 at $2 \times 10^{9} \mathrm{CFU} / \mathrm{kg}$, during broiler production period of 1 to 42 days of age increased the cecal relative abundance of beneficial microbiome, upregulated the expression of some antiinflammatory cytokines, and downregulated the expression of some proinflammatory cytokines. Thus, it can cause the reduction of gut pathogens. Similarly, the amino acids and peptides transporter genes expressions were also enhanced in both antibiotic and probiotic fedgroups when compared with the control group. In addition, sugar transporter related genes were upregulated by $B$. subtilis probiotic fed-group compared to antibiotic and control group. The overall results clearly confirmed the potential of B. subtilis DSM 32315 probiotic against $C$. perfringens bacteria causing necrotic enteritis infection, 
and thus it could be used as an alternative to AGPs from day one to day 42 of production period in broiler chickens.

\section{DECLARATIONS}

\section{Consent to publish}

All authors have approved to publish the work

\section{Competing interests}

The authors declare that they have no conflict of interests.

\section{Author`s contributions}

The conceptualization was done by Bello $\mathrm{M}$. Bodinga and XiaoJun Yang. The methodology was designed by Rab N. Soomro, Khawar Hayat, JinHui Zhou and Xinshuai Liu. Validation and formal analysis were performed by Abdullahi Ismaila and Zhouzheng Ren.

\section{Acknowledgments}

The authors appreciate the financial support provided by Evonik Nutrition and Care GmbH, (Hanau, Germany). This work was supported by the National Key Research and Development Program of China (2017YFD0500500, 2017YFD0502200) and the Program for Shaanxi Science \&Technology (2017TSCXLNY-04-04, 2018ZDCXL-NY0201,2018ZDXM-NY-051) and the Program for Yangling Agricultural High-tech Industries Demonstration Zone (2018CXY-10).

\section{REFERENCES}

Apajalahti J (2005). Comparative Gut Microflora, Metabolic Challenges and Potential Opportunities. Journal of Applied Poultry Research, 14: 444-453. DOI:https://doi.org/10.1093/japr/14.2.444

Bai Huang Q, Zhang J, He J, Zhang L and Wang T (2017). Supplemental effects of probiotic Bacillus subtilis fmbJ on growth performance, antioxidant capacity, and meat quality of broiler chickens. Poultry Science, 96: 74-82. DOI: https://doi.org/10.3382/ps/pew246

Barbosa TM, Rm SCR, Woodward MJ and Henriques AO (2005). Screening for bacillus isolates in the broiler gastrointestinal tract. Applied and Environmental Microbiology, 71(2): 968-978. DOI:https://dx.doi.org/10.1128\%2FAEM.71.2.968-978.2005

Binek (2012). Mikrobiom człowieka, zdrowie i choroba. Postępy Mikrobiologii, 51: 27-36. http://www.pm.microbiology.pl

Cao L, Yang X J, Li ZJ, Sun FF, Wu XH and Yao JH (2012). Reduced lesions in chickens with Clostridium perfringens-induced necrotic enteritis by Lactobacillus fermentum 1.20291. Poultry Science, 91: 3065-3071. DOI: http://dx.doi.org/10.3382/ps.2013-92-4-1143

Chen CY, Tsen, HY, Lin CL, Yu B and Chen CS (2012). Oral administration of a combination of select lactic acid bacteria strains to reduce the Salmonella invasion and inflammation of broiler chicks. Poultry Science, 91: 2139-2147. DOI: https://doi.org/10.3382/ps.2012-02237
Cochrane SA and Vederas JC (2016). Lipopeptides from Bacillus and Paenibacillus spp. A gold mine of antibiotic candidates. Medical Research Review, 36: 4-31. DOI:https://doi.org/10.1002/med.21321

Collier CT, Hofacre CL, Payne AM, Anderson DB, Kaiser P, Mackie RI and Gaskins HR (2008) Coccidia-induced mucogenesis promotes the onset of necrotic enteritis by supporting Clostridium Perfringens growth. Veterinary Immunology and Immunopathology, 122(1): 104-115. DOI: https://doi.org/10.1016/j.vetimm.2007.10.014

Dahiya JP, Wilkie DC, Kessel AG and Drew MD (2006). Potential strategies for controlling necrotic enteritis in broiler chickens in post-antibiotic era. Animal Feed Science and Technology, 129(1): 60-88. DOI: http://dx.doi.org/10.1016/j.anifeedsci.2005.12.003

Dahiya JPD, Hoehler AG, Van Kessel and Drew MD (2007). Dietary encapsulated glycine influences Clostridium perfringens and Lactobacilli growth in the gastrointestinal tract of broiler chickens. Journal of Nutrition, 137: 1408-1414. DOI: https://doi.org/10.1093/jn/137.6.1408

Dibner JJ and Richards JD (2005). Antibiotic growth promoters in agriculture: history and mode of action. Poultry Science, 84(4): 634-643. DOI: https://doi.org/10.1093/jn/137.6.1408

GaddeU, Kim Oh ST and Lillehoj HS (2017). Alternatives to antibiotics for maximizing growth performance and feed efficiency in poultry: a review. Animal Health Research Reviews, 18: 26-45 DOI: https://doi.org/10.1017/s1466252316000207

Gilbert ERH, Li DA, Emmerson KE, Webb J and Wong EA (2008). Dietary protein quality and feed restriction influence abundance of nutrient transporter mRNA in the small of broiler chickens. Journal of Nutrition, 138: 262-271. DOI: https://doi.org/10.1093/jn/138.2.262

Gronow S, Held B, Lucas S, Lapidus A, Rio TGD, Nolan M and Pitluck S (2011). Complete genome sequence of Bacteroides salanitronis type strain (BL78T). Standards in Genomic Sciences, 4(2): 191199. DOI: https://doi.org/10.4056/sigs.1513795

Hayat K, Bodinga BM, Han D, Xin Y, Sun Q, Aleya L, MM Abdel-Daim and Yang X (2019). Effects of dietary inclusion of chromium propionate on growth performance, intestinal health, immune response and nutrient transporter gene expression in broilers. Science of the Total Environment. 705:13:58-69. DOI: https://doi.org/10.1016/j.scitotenv.2019.135869

Heilig HG, Zoetendal EG, Vaughan EE, Marteau P, Akkermans AD and de Vos WM (2002). Molecular Diversity of Lactobacillus spp. and other lactic acid bacteria in the human intestine as determined by specific amplification of $16 \mathrm{~S}$ ribosomal DNA, Applied Environmental Microbiology, 68(1): 114-123. DOI: https://doi.org/10.1128/aem.68.1.114-123.2002

Hill DA, Hoffmann C, Abt MC, Du Y, Kobuley D, Kirn TJ and Artis D (2010). Metagenomic analyses reveal antibiotic-induced temporal and spatial changes in intestinal microbiota with associated alterations in immune cell homeostasis. Mucosal Immunology, 3: 148-158. DOI: https://doi.org/10.1038/mi.2009.132

Hooge DM, Sims MD, Sefton AE, Connolly A and Spring P (2003). Effect of Dietary Mannan Oligosaccharide, With or Without Bacitracin or Virginiamycin, on Live Performance of Broiler Chickens at Relatively High Stocking Density on New Litter. Journal of Applied Poultry Research, 12(4): 461-467. DOI:https://doi.org/10.1093/japr/12.4.461

Hooper LV, Midtvedt T and Gordon JI (2002). How host-microbial interactions shape the nutrient environment of the mammalian intestine [Review]. Annual Review of Nutrition, 22: 283-307.DOI: https://doi.org/10.1146/annurev.nutr.22.011602.092259

Jeong JS and Kim IH (2015). Effect of fermented medicinal plants Gynura procumbens, Rehmannia glutinosa, Scutellaria baicalensis as alternative performance enhancers in broilers. Japan Poultry Science, 52:119-216. DOI:https://doi.org/10.2141/jpsa.0140061 
Knap I, Kehlet AB, Bennedsen M, Mathis GF, Hofacre CL, Lumpkins BS and Lay A (2011). Bacillus subtilis (DSM17299) significantly reduces Salmonella in broilers. Poultry Science, 90(8): 1690-1694 DOI: https://doi.org/10.3382/ps.2010-01056

Latorre JD, Hernandez-Velasco X, Kallapura G, Menconi A, Pumford NR and Morgan MJ (2014). Evaluation of germination, distribution and persistence of Bacillus subtilis spore through the gastrointestinal tract of chickens. Poultry Science, 93: 1793-1800. DOI: https://doi.org/10.3382/ps.2013-03809

Lee K, Lillehoj HS and Siragusa GR (2010) Direct-Fed Microbials and Their Impact on the Intestinal Microflora and Immune System of Chickens. Journal of Poultry Science, 47: 2: 106-114 DOI:https://doi.org/10.2141/jpsa.009096

Lee KW, Li G, Lillehoj HS, Lee SH, Jang SI, Babu US and Siragusa GR (2011) Bacillus subtilis-based direct-fed microbials augment macrophage function in broiler chickens. Research in Veterinary Science, $91(3)$ : $87-91 . \quad$ DOI: https://doi.org/10.1016/j.rvsc.2011.01.018

Li X, Wu S, Li X, Yan T, Duan Y, Yang X and Yang X (2018). Simultaneous Supplementation of Bacillus subtilis and Antibiotic Growth Promoters by Stages Improved Intestinal Function of Pullets by Altering Gut Microbiota. Frontiers in Microbiology. 9: 2328-2343. DOI: https://doi.org/10.3389/fmicb.2018.02328

Liu L, Xu X, Cao Y, Cai C, Cui H and Yao JDS (2017). Nitrate decreases methane production also by increasing methane oxidation through stimulating NC10 population in ruminal culture. AMB Express, 7: 76-82. DOI: https://doi.org/10.1186/s13568-017-0377-2

Livak KJ and Schmittgen TD (2001). Analysis of relative gene expression data using real-time quantitative PCR and the $2-\Delta \Delta C T$ method. Methods. 25: 4 402-408 DOI: https://doi.org/10.1006/meth.2001.1262

Marta D, Andrzej P, Renata UC and Andrzej W (2014). Screening of Lactobacillus strains of domestic goose origin against bacterial poultry pathogens for use as probiotics. Poultry Science, 93 (10): 2464-2472. DOI: https://doi.org/10.3382/ps.2014-04025

Minas K, McEwan NR, Newbold CJ and Scott KP (2011). Optimization of a high-throughput CTAB-based protocol for the extraction of qPCR-grade DNA from rumen fluid, plant and bacterial pure cultures. FEMS Microbiology Letters, 325(2): 162-169. DOI: https://doi.org/10.1111/j.1574-6968.2011.02424.x

Mountzouris KC, Dalaka E, Palamidi I, Paraskeuas V, Demey V, Theodoropoulos G and Fegeros K (2015). Evaluation of yeast dietarysupplementation in broilers challenged or not with Salmonella on growth performance, cecal microbiota composition and Salmonella in ceca, cloacae and carcass skin. Poultry Science, 94: 10: 2445-2455. DOI: https://doi.org/10.3382/ps/pev243

Musa BB, Duan Y, Khawar H, Qingzhu S, Zhouzheng R, Mohamed AEM, Imtiaz HRA and Xiaojun Y (2019). Bacillus subtilis B21 and Bacillus licheniformis B26 improve intestinal health and performance of broiler chickens with Clostridium perfringensinduced necrotic enteritis. Journal Animal Physiology Anim Nutrition (Berl), 103(4): 1039-1049. DOI: https://doi:10.1111/jpn.13082

Oh ST and Lillehoj HS (2016). The role of host genetic factors and host immunity in necrotic enteritis. Avian Pathology, 45:3: 1-11. DOI: https://doi.org/10.1080/03079457.2016.1154503

Opengart JS, Swayne DE, Glisson JR, McDougald LR, Nolan Lisa K, Venugopal N and Ames I (2013). Necrotic Enteritis Diseases of Poultry. Ames. USA, 13th ed. pp. 949-953..

Palamidi I, Fegeros K, Mohnl M, Abdelrahman W, Schatzmayr G, Theodoropoulos G and Mountzouris KC (2016). Probiotic form effects on growth performance, digestive function, and immune related

biomarkers in broilers. Poultry science, 95:7: 1598-1608. DOI: https://doi.org/10.3382/ps/pew052
Park JH and Kim IH (2014). Supplemental effect of Probiotic Bacillus subtilis B2A on productivity, organ weight, intestinal Salmonella microflora, and breast meat quality of growing broiler chicks. Poultry Science, 93: 2054-2059. DOI: https://doi.org/10.3382/ps.2013-03818

Pyoung K, Young JM, Young-Hyo C, Saehun K, Seong- Jae K and Yong-Ha P (2007) Probiotic properties of Lactobacillus and Bifidobacterium strains isolated from porcine gastrointestinal tract. Applied Microbiology and Biotechnology, 745: 1103-1111. DOI: https://doi.org/10.1007/s00253-006-0741-7

Rajput IR, Ying H, Yajing S, Arain MA, Weifen L, Ping L, Bloch DM and Wenhua L (2017). Saccharomyces boulardii and Bacillus subtilis B10 modulate TLRs and cytokines expression patterns in jejunum and ileum of broilers. PLoS ONE 12 (6): e0180752. DOI: https://doi.org/10.1371/journal.pone.0180752

Statistical Analysis System (SAS), Base SAS 9.4. (2015). procedures guide: $5^{\text {th }}$ ed. Carry, NC: SAS Institute Inc. Statistical procedures: SAS Institute Inc. Available at: http://support.sas.com.

Shaufi M, Chin Chin S, Chun Wie C, Ming GH and Wan HY (2015). dynamics based on high-throughput 16S rRNA metagenomics analyses. Gut Pathogens, 7: 1-12. DOI: https://doi.org/10.1186/s13099-015-0051-7

Shivaramaiah SN, Pumford M, Morgan R, Wolfenden A, Wolfenden A, Torres-Rodriguez and Téllez G (2011). Evaluation of Bacillus species as potential candidates for direct-fed microbials in commercial poultry. Poultry Science, 90: 1574-1580. DOI: https://doi.org/10.3382/ps.2010-00745

Shoemaker SP and Pierson MD (1976). "Phoenix phenomenon" in the growth of Clostridium perfringens. Applied and Environmental Microbiology. 32(6):803-807

Simon O, Jadamus A and vahjen W (2001). Probiotic feed additives effectiveness and expected modes of action. Journal of Animal and Feed Sciences, 10: 51-67. DOI: https://doi.org/10.22358/jafs/70012/2001

Stanley D, Hughes, RJ and Moore RJ (2014). Microbiota of the chicken gastrointestinal tract: influence on health, productivity and disease. Applied Microbiology and Biotechnology, 98: 4301- 4310. DOI: https://doi.org/10.1007/s00253-014-5646-2

Stanley D, Keyburn AL, Denman SE and Moore RJ (2012). Changes in the cecal microflora of Chickens following Clostridium perfringens Challenge to induce necrotic enteritis. Veterinary Microbiology, 59: 155-162. DOI: ttps://doi.org/10.1016/j.vetmic.2012.03.032

Su S, Miska KB. Fetterer RH, Jenkins MC and Wong EA (2014). Expression of digestive enzymes and nutrient transporters in Eimeria acervulina-challenged layers and broilers. Poultry science, 93(5): 1217-1226. DOI: https://doi.org/10.3382/ps.2013-03807

Sumi C, Yang B, Yeo IC and Hahm Y (2015). Antimicrobial peptides of the genus Bacillus: a New era for antibiotics. Canadian Journal of Microbiology, 61: 93-103. DOI: https://doi.org/10.1139/cjm-2014$\underline{0613}$

Tellez G, Higgins SE, Donoghue AM and Hargis BM (2006). Digestive Physiology and the Role of Microorganisms. Journal of Applied Poultry Research,15: 136-144. DOI: https://doi.org/10.1093/japr/15.1.136

Teo AYL and Tan HM (2005). Inhibition of Clostridium perfringens by a novel strain of Bacillus subtilis isolated from the gastrointestinal tracts of healthy chickens. Applied Environmental Microbiology, 71: 4185- 4190. DOI: https://dx.doi.org/10.1128/AEM.71.8.4185$\underline{4190.2005}$

Timbermont L, Haesebrouck F, Ducatelle R and Van Immerseel F (2011). Necrotic enteritis in broilers: an updated review on the pathogenesis. Avian Pathology, 40(4): 341-347. DOI: https://dx.doi.org/10.1080/03079457.2011.590967

Wade B and Keyburn A (2015). The true cost of necrotic enteritis. World Poultry, 31, 16-17. Availabe at: 
http://www.worldpoultry.net/Broilers/General/2015/10/The-truecost-of-necrotic-enteritis-2699819W/

Walter J, Hertel C, Tannock GW, Lis CM, Munro K and Hammes WP (2001). Detection of Lactobacillus, Pediococcus, Leuconostoc and Weissella Species in Human Feces by Using Group-Specific PCR Primers and Denaturing Gradient Gel Electrophoresis. Applied and Environmental Microbiology, 67: 2578-2585 DOI: https://doi.org/10.1128/AEM.67.6.2578-2585.2001

World Health Oranization (WHO) (2017). Antibiotic resistance, stop using antibiotics in healthy animals to prevent the spread of antibiotic resistance. newsletter release. News letter.

Wielen PW, Biesterveld S, Notermans S, Hofsra H, Urlings BA and Van Knapen F (2000). Role of Volatile Fatty Acids in Development of the Cecal Microflora in Broiler Chickens during Growth. Applied and Environmental Microbiology, 66 (6): 2536-2540. DOI: https://doi.org/10.1128/aem.66.6.2536-2540.2000

Wise MG and Siragusa GR (2005). Quantitative detection of Clostridium perfringens in the broiler fowl gastrointestinal tract by real-time PCR Applied Environmental Microbioloy, 71(7): 3911-3916 DOI: https://doi.org/10.1128/AEM.71.7.3911-3916.2005

Xiao Y, Xiang Y, Zhou W, Chen J and Li KHY (2017). Microbial community mapping in intestinal tract of broiler chicken. Poultry Science, 96: 1387-1393. DOI: https://doi.org/10.3382/ps/pew372

Zhao PY and Kim IH (2015). Effect of direct-fed microbial on growth performance, nutrient digestibility, fecal noxious gas emission, fecal microbial flora and diarrhea score in weanling pigs. Animal Feed Science Technology 200: 86-92. DOI: https://doi.org/10.1016/j.anifeedsci.2014.12.010 